\title{
Coronary steal: Revealing the diagnosis with quantitative cardiac PET/CT
}

\author{
Mechteld Heijne, MD, ${ }^{\mathrm{a}, \mathrm{b}}$ Pieter G. Raijmakers, MD, PhD, ${ }^{\mathrm{a}, \mathrm{b}}$ Hendrik J. Harms, \\ MSc, ${ }^{\text {a,b }}$ Mark Lubberink, PhD, ${ }^{\mathrm{a}, \mathrm{b}}$ Rick Halbmeijer, MD, ${ }^{\mathrm{c}}$ Yolande E. Appelman, \\ $M D,{ }^{c}$ and Paul Knaapen, $M D, P^{c}$
}

A 68-year-old male was evaluated at our chest pain unit because of recent onset exertional anginal chest pain. The symptoms commenced after an initial episode of angina that had lasted for several hours. The electrocardiogram (ECG) showed signs of a recent inferior myocardial infarction (Figure 1) after which the patient was treated with antiplatelet agents, a statin, and beta-blockers. To further evaluate the extent of coronary artery disease and ischemia, a cardiac PET/ CT was performed. The imaging protocol consisted of a 64-slice CT coronary angiography (CTCA) and myocardial perfusion measurements using oxygen-15labeled water PET during rest and pharmacologically induced vasodilation (adenosine). During vasodilation, the patient reported anginal chest pain and the ECG displayed ST-segment elevation in the Q-wave leads suggestive of transmural inferior ischemia, although it should be noted that stress-induced ST segment elevation in Q-leads may also occur in the absence of ischemia. Heart rate and blood pressure did not change appreciably during the stress study, and the ECG abnormalities and symptoms resolved immediately after termination of adenosine infusion. CTCA revealed an occlusion of the right coronary artery (RCA) with collateral filling of the distal segment (Figure 2). PET images displayed a mild resting perfusion defect in the inferior wall (Figure 3). During hyperemia, the

From the Department of Nuclear Medicine and PET Research, ${ }^{a}$ VU University Medical Center, Amsterdam, The Netherlands; Department of Nuclear Medicine, 4F 005, ${ }^{\mathrm{b}}$ VU University Medical Center, Amsterdam, The Netherlands; and Department of Cardiology, ${ }^{\mathrm{c}} \mathrm{VU}$ University Medical Center, Amsterdam, The Netherlands.

Reprint requests: Mechteld Heijne, MD, Department of Nuclear Medicine, 4F 005, VU University Medical Center, De Boelelaan 1117, 1081 Amsterdam, The Netherlands; m.heijne@vumc.nl.

J Nucl Cardiol 2010;17:1118-21.

$1071-3581 / \$ 34.00$

Copyright $\odot 2010$ The Author(s). This article is published with open access at Springerlink.com

doi:10.1007/s12350-010-9265-8 perfusion defect expanded toward the inferior distal wall and part of the septum and lateral wall. Of interest, quantitative perfusion analysis displayed a restflow in the RCA perfusion territory of $0.70 \mathrm{~mL} /$ minute/g of perfusable tissue, which paradoxally decreased during hyperemia to $0.49 \mathrm{~mL} /$ minute $/ \mathrm{g}$, yielding a flow reserve of 0.7 (Figure 4). The patient was referred for invasive coronary angiography, which confirmed the occlusion of the RCA (Figure 5). In addition, a significant stenosis of the margo obtusis branche of the circumflex coronary artery was detected, compatible with the reduced flow reserve in the circumflex perfusion territory (Figure 4). Through a percutaneous coronary intervention, both RCA and circumflex lesions were stented and the patient was discharged free of symptoms.

During stress testing with vasodilators such as adenosine or dipyridamol, generally a condition of luxury perfusion occurs, i.e., vasomotor autoregulation is abolished and perfusion exceeds metabolic demand. Consequently, ischemia is not routinely observed during administration of these agents. The principle to detect a flow limiting coronary stenosis is based on the relative impairment to increase perfusion during maximum vasodilation in comparison with myocardium subtended by a non-stenotic reference vessel, irrespective of the myocardial metabolic demand at the time of the vasodilation study. In the currently described patient, however, transmural ischemia was induced by adenosine which could not be attributed to increased metabolic demand as the rate-pressure product remained stable during the stress study. Instead, maximum vasodilation induced a coronary steal syndrome of collateral-dependent myocardium. Studies have demonstrated that coronary collaterals are pre-existing channels, consisting of interconnecting anastomotic vessels (IAVs) rather than being actively formed. ${ }^{1}$ During circumstances of a critical coronary stenosis or occlusion, a pressure drop is created in the IAVs, which cause dilatation of the IAVs and thereby induce a collateral circulation. Under hyperemic conditions, due to vasodilator-agents or exercise, resistance in the normal 

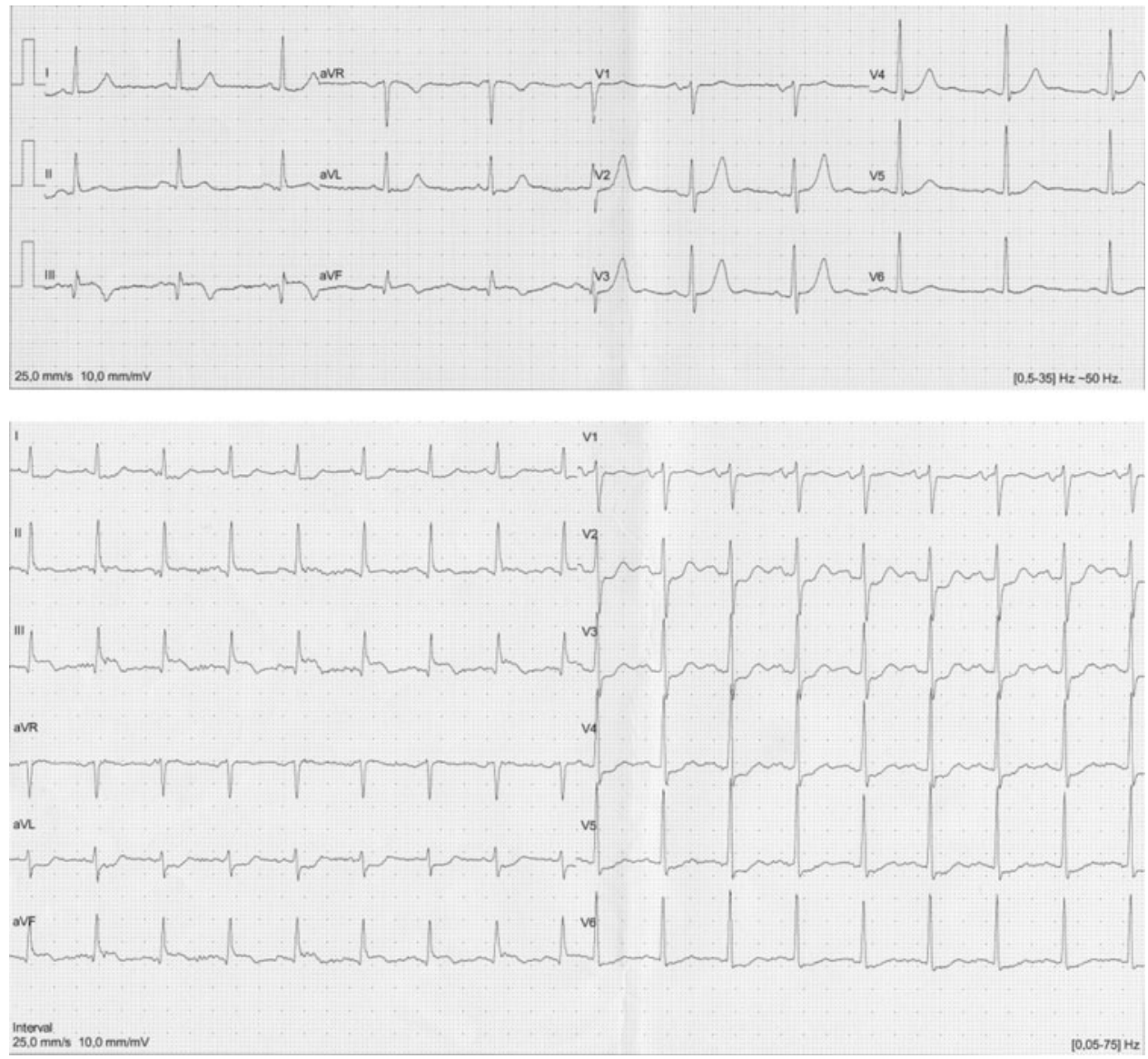

Figure 1. Upper row: baseline ECG compatible with subacute inferior wall myocardial infarction. Lower row: ST-segment elevation in lead III, AVF with reciprocal depression in leads AVL and V2-4 during stress.

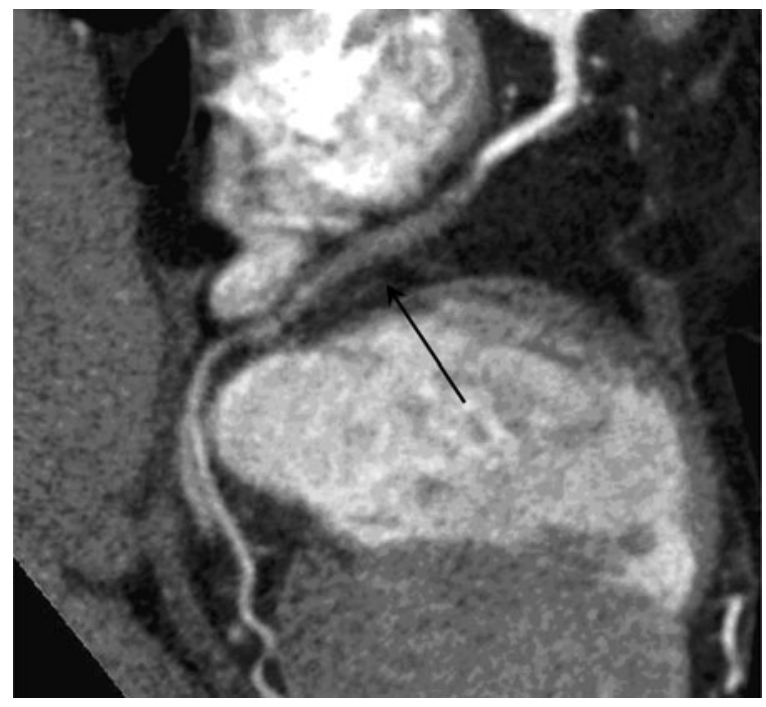

Figure 2. CTCA shows total occlusion of midtraject of the RCA, the distal segment shows contrast opacification caused by collateral filling. coronary artery falls, resulting in augmented perfusion in areas without a stenosis and a reduced collateral flow to the stenotic or occluded artery segment. Since vasodilation in the latter area is already maximal, coronary perfusion actually decreases in collateraldependent myocardium. ${ }^{2-4}$ Although data are limited, coronary steal may occur in as many as $10 \%$ of patients with coronary artery disease during pharmacological stress. ${ }^{5,6}$

In routine clinical practice, however, this phenomenon is not easily detected as a reduction in absolute levels of perfusion in the collateral-dependent myocardium during vasodilation is a prerequisite to diagnose coronary steal syndrome. ${ }^{7,8}$ The combination of PET/CT enables to measure absolute quantitative perfusion in combination with visualization of coronary anatomy. As illustrated in the current case, this new form of hybrid imaging therefore facilitates the identification of collateral-dependent myocardium in a non-invasive manner. 


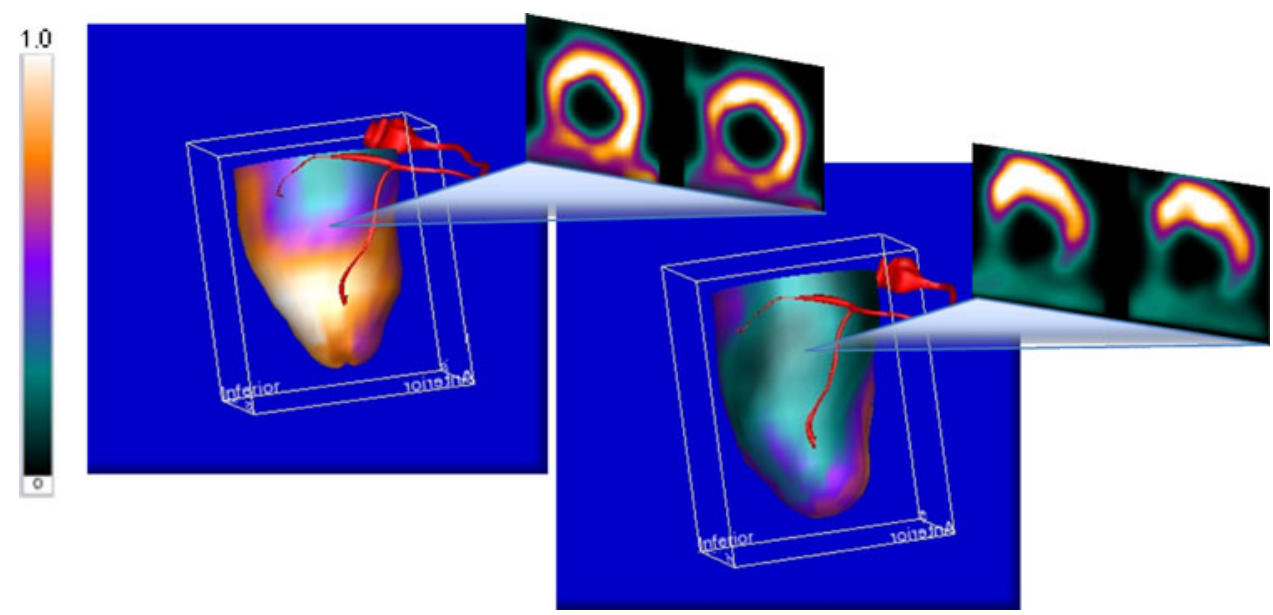

Figure 3. 3D fusion of the parametric perfusion PET, with the RCA derived from the CTCA, during rest (left) and vasodilation (right) with corresponding colorscale of absolute perfusion ranging from 0 to 1.0 expressed in $\mathrm{mL} / \mathrm{minute} / \mathrm{g}$ of perfusable tissue. The PET/CT stress images reveal a small perfusion defect during rest which expands to the inferior, inferoseptal, and inferolateral wall during vasodilation.

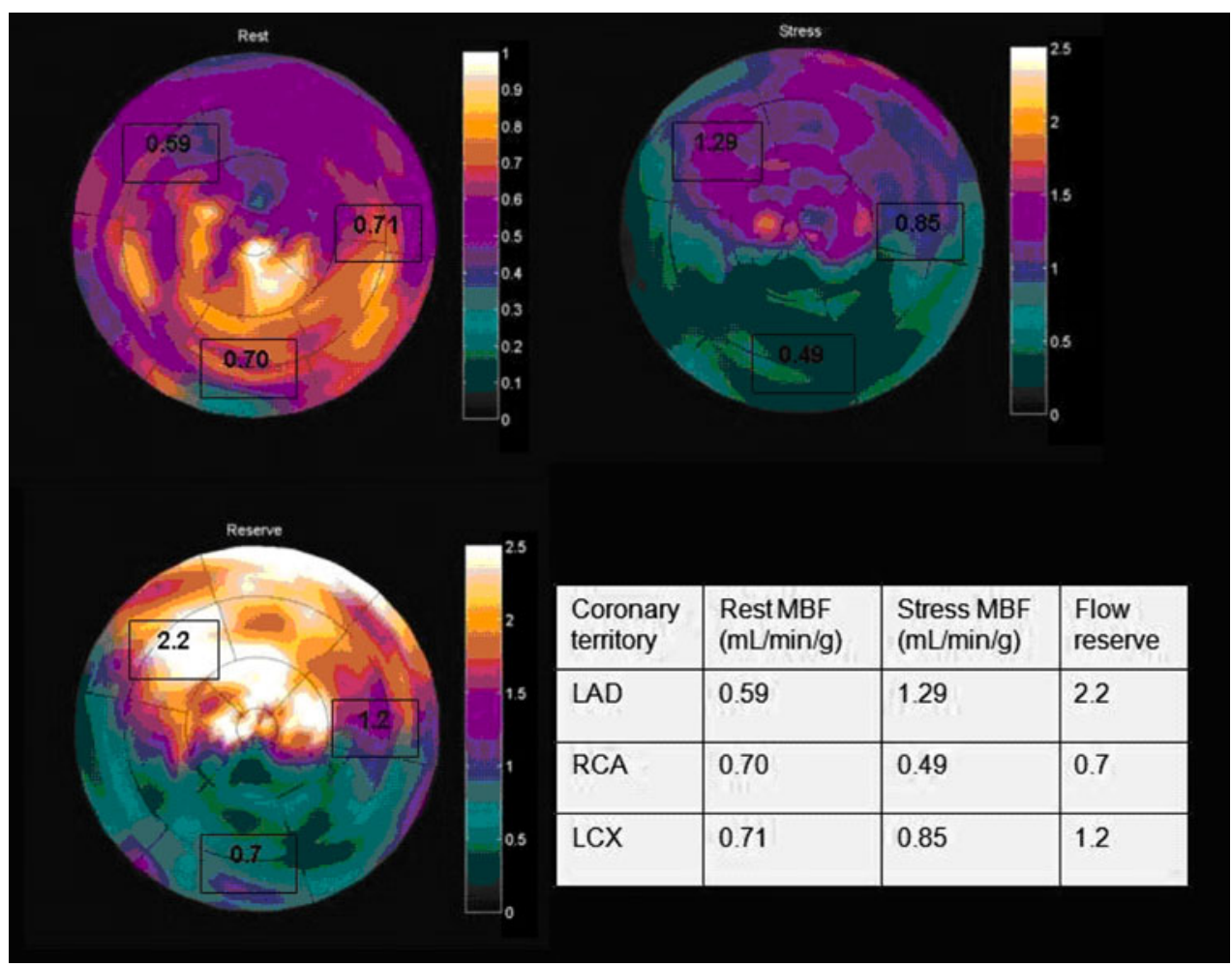

Figure 4. Parametric polar map of absolute quantitative myocardial perfusion $(\mathrm{mL} / \mathrm{minute} / \mathrm{g}$ of perfusable tissue) at rest (right upper quadrant), stress (left upper quadrant), and flow reserve (left lower quadrant). A decreased flow reserve is displayed in inferior, inferolateral, and inferoseptal wall with according quantitative parameters. 

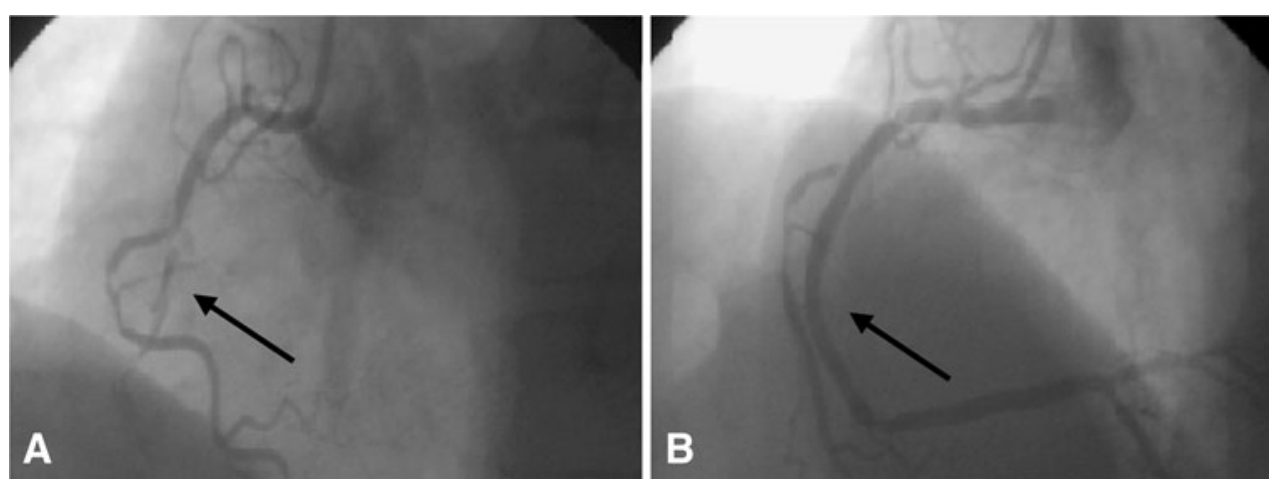

Figure 5. Angiographic images showing the coronary lesion of the RCA before (A) and after stenting (B). Arrow indicates coronary lesion.

\section{Open Access}

This article is distributed under the terms of the Creative Commons Attribution Noncommercial License which permits any noncommercial use, distribution, and reproduction in any medium, provided the original author(s) and source are credited.

\section{References}

1. Levin DC. Pathways and functional significance of the coronary collateral circulation. Circulation 1974;50:831-7.

2. Becker L. Conditions for vasodilator-induced coronary steal in experimental myocardial ischemia. Circulation 1978;57:1103-10.

3. Patterson R, Kirk E. Coronary steal mechanism in dogs with onevessel occlusion and other arteries normal. Circulation 1983;67: 1009-15.
4. Werner GS, Fritzenwanger M, Prochnau D, Schwarz G, Ferrari M, Aarnoudse W, Pijls NHJ, Figulla HR. Determinants of coronary steal in chronic total coronary occlusions: Donor artery, collateral, and microvascular resistance. J Am Coll Cardiol 2006;48:51-8.

5. Seiler C, Fleisch M, Meier B. Direct intracoronary evidence of collateral steal in humans. Circulation 1997;96:4261-7.

6. Werner GS, Figulla HR. Direct assessment of coronary steal and associated changes of collateral hemodynamics in chronic total coronary occlusions. Circulation 2002;106:435-40.

7. Chareonthaitawee P, Kaufmann PA, Rimoldi O, Camici PG. Heterogeneity of resting and hyperemic myocardial blood flow in healthy humans. Cardiovasc Res 2001;50:151-61.

8. Dekemp RA, Yoshinaga K, Beanlands RSB. Will 3-dimensional PET-CT enable the routine quantification of myocardial blood flow? J Nucl Cardiol 2007;14:380-97. 